\title{
DO PERSONALITY AND GENDER MITIGATE THE ADVERSE EFFECTS OF EMOTIONAL LABOR? EMPIRICAL EVIDENCE FROM HEALTHCARE DURING COVID-19 PANDEMIC
}

\author{
Saman Javed $^{1 *}$, Noshaba Batool ${ }^{2}$
}

${ }^{1 *}$ Ph.D., Scholar (Management Sciences), Air University School of Management, Islamabad, Pakistan; ${ }^{2}$ Assistant Professor, Air University School of Management, Islamabad, Pakistan.

Email: ${ }^{*}$ samanjaved95@gmail.com, ${ }^{2}$ nbsyedahmed@gmail.com

Article History: Received on $23^{\text {rd }}$ March 2021, Revised on $5^{\text {th }}$ April 2021, Published on $9^{\text {th }}$ April 2021

\begin{abstract}
Purpose: The impact of emotional labor on organizational outcomes is contingent upon numerous factors. Moreover, after the outbreak of the COVID-19 pandemic worldwide, the implications of emotional labour practices, especially among physicians, have become more uncertain. This study aims to address these notions by examining the multigroup moderating effect of social and enterprising personalities and gender on a model of emotional labour. The aim is to determine whether emotional labour affects emotional exhaustion and well-being varies across these groups.
\end{abstract}

Methodology: Serial mediation and multigroup moderation methods were employed to test the proposed hypotheses. Data was collected from 400 physicians across Pakistan. Snowball sampling method was adopted for data collection. Structural equation modelling, including serial mediation and multigroup moderation techniques were employed for data analysis.

Main Findings: Physicians with highly social personalities and low enterprising personalities are more likely to experience detrimental effects of surface acting. Genuine emotions improve well-being for high social and enterprising as well as low enterprising personality physicians. No across-group differences exist for deep acting. For gender, females are found to be more susceptible to negative repercussions of emotional labor than their male counterparts. Positive effect of genuine emotions remains somewhat the same for both.

Implications/Applications: This study assists healthcare organizations in making the right choices during the recruitment and selection process to choose the most suitable candidates for tasks involving emotional labor, i.e., ones whose personality and gender attributes are aligned with the affective or emotional component of work. This would aid in ensuring doctors' high psychological and physical well-being at work.

Novelty/Originality of this study: This research proposes a model of emotional labour strategies and their effects on physicians' emotional exhaustion and well-being. Multigroup moderating effects of two personality types, i.e., social and enterprising, and gender, are investigated with respect to the proposed model to see if there lie any differences between physicians belonging to various personality or gender groups.

Keywords: COVID-19, Emotional Labor, Enterprising Personality, Social Personality, Hedonic Well-being, Eudaimonic Well-being, Physical Well-being, Emotional Exhaustion, Gender.

\section{INTRODUCTION}

Emotional labor and regulation have become an important part of service interactions. To enhance customer experience, the display of certain emotions is now a formal part of jobs (Gabriel, Acosta, \& Grandey, 2015). However, meeting the emotional demands of work is a tiring requirement and may even cause grave problems like depression and anxiety (Yin, Huang, \& Lv, 2018). Lack of emotional stability leads to emotional exhaustion and strain among personnel (David et al., 2020). If not addressed, this may escalate to low morale and well-being and high turnover intentions (Hur, Moon, \& Jun, 2016; Heijden, Mahoney, \& Xu, 2019).

Practising emotional labor in fields like medicine carries challenges that are far more severe relative to other occupations. Especially after the outbreak of the COVID-19 pandemic worldwide, the propensity towards emotional instability and emotional exhaustion has further increased (Sinnott, Georgiadis, Park \& Dixon-Woods, 2020). This is particularly true for doctors and physicians who are not only working in high-risk environments but are also more likely to experience mental and emotional exhaustion (Shaukat, Ali, \& Razzak, 2020). One must have emotional or affective resources to combat the adverse effects of emotional labor. Here, the role of a physician's own personality and gender may play a key role in determining how emotions affect them during the pandemic.

\section{Impact of COVID-19 Pandemic on Healthcare Sector}

In addition to the existing challenges associated with practising emotional labor in healthcare, the spread of the COVID-19 virus presents some major hurdles for healthcare personnel. From patient care and prolonged working hours to the high 
probability of infection of self or a family member, COVID-19 has considerably taken a toll on healthcare workers' mental well-being. Furthermore, an increasing number of cases has overwhelmed the healthcare systems worldwide. Limited medical facilities, violation of SOPs, and low probability of herd immunity are important factors that contribute to high rising COVID cases (Khalid \& Ali, 2020: Shaukat, Ali, \& Razzak, 2020). The overburden stemming out of providing medical care, combined with pandemic related challenges, has led the healthcare workers to experience low mental and psychological well-being in the form of stress, anxiety, distress, and depression; and low physical well-being in the form of fatigue and poor sleep (Bhuyan, 2020: Shreffler, Petrey \& Huecker, 2020).

Jobs of healthcare workers, especially doctors and physicians, already entail emotional composure and emotional acting in front of patients, attendants, and visitors. Adding the factor of a pandemic has made it even more challenging than before. Thus, doctors' emotional regulation and stability at work are now as important as the job itself (Bhuyan, 2020: Murthy, Gomersall, \& Fowler, 2020). This level of focus and motivation required to keep working during the pandemic has led healthcare workers to demand considerable raises in compensation (Sinnott, Georgiadis, Park \& Dixon-Woods, 2020).

It must also be noted that the impact of emotional labour on emotional exhaustion and well-being during the COVID pandemic may not be uniform for all healthcare workers. Understandably so, there can always be individual differences among workers in dealing with the pandemic's emotional challenges. For instance, there are significant differences among males and females in dealing with the pandemic's social aspect. Similarly, extroverts are better equipped to cope with distress during a pandemic by seeking social interaction (Volk et al., 2021), while workers high on conscientiousness are more likely to be cautious about the due procedures and SOPs (Aschwanden, 2020). Factors like personality, gender, and culture may heighten or mitigate pandemic adverse effects (Jeronimus, 2020).

Based upon the above discussion, this study proposes a model of emotional labor strategies, with their effects on emotional exhaustion and well-being among physicians. Multigroup moderating effects of two personality types, i.e., social and enterprising, and gender, are investigated to see if there lie any differences between physicians belonging to various personality or gender groups. A research model is based on the Conservation of Resource (COR) theory and Job-DemandsResources (JDR) model. The former states that individuals need to have ample emotional resources to maximize gains and minimize losses. Conservation of these resources enhances one's ability to deal with loss, strain, or exhaustion. Paradoxically, losses provide the urge to gain back emotional resources (Hobfoll, 1989; 2018). JDR theory states that jobs in any organisation entail certain demands like physical workload, work shifts, time pressures, environment, etc. These demands are met by workers who possess resources like rewards, participation, job security, job control, and supervisor support (Demerouti et al., 2001). JDR theory is an extension of COR theory. Both suggest that a mismatch between the job demands and job resources leads to negative effects like stress, exhaustion, burnout, and disengagement (Hobfoll, 1989; Demerouti et al., 2001; Hobfoll, 2011).

\section{The rationale of the study and purpose of the study}

Given the presence of COVID-19 context in healthcare, it is proposed that physicians choose emotional labor strategies that would help in balancing emotional job demands and emotional resources and conserve those resources to minimize losses. The model also proposes that having a certain personality or belonging to a specific gender group may aid in effective emotional management and regulation among physicians during the pandemic.

\section{LITERATURE REVIEW}

\section{Emotional Labor and Emotional Exhaustion}

Emotional labor entails expressing a person's emotions at work (Ashforth \& Humphrey, 1993). There are three facets of emotional labor. Surface acting is the fake display of emotions when workers only play their part by pretending to have certain emotions. Conversely, deep acting involves internalizing the displayed emotions to create a harmony between showed and felt emotions (Hochschild, 1979). Genuine emotions involve displaying genuine and authentic emotions, not relying upon acting or internalizing the emotions, rather showing naturally felt emotions to others (Ashforth \& Humphrey, 1993). Choosing the right emotional labor strategy can help reduce affective resource depletion and effectively meet emotional job demands (McCauley \& Gardner, 2015).

Emotional labor is closely tied to emotional exhaustion. Emotional exhaustion refers to the state of acute and overwhelming strain resulting from tough job demands (Maslach \& Leiter, 2016). Depletion of emotional resources to meet these demands eventually lead to emotional exhaustion (Maslach, Schaufeli, \& Leiter, 2001). It can further cause stress (Golparvar, 2016), high turnover intentions, and low well-being (Heijden, Mahoney, \& Xu, 2019). Numerous studies have found the significant impact of emotional labor on emotional exhaustion (Zhan, Wang, \& Shi, 2015; Hu, Hu, \& King, 2016; Chen, Chang, \& Wang, 2019). However, different emotional labor strategies have varying effects. Surface acting usually increases emotional exhaustion (Liu et al., 2019; Gulsen \& Ozmen, 2020). On the other hand, deep acting reduces emotional exhaustion (Liu et 
al., 2019; Yu, Kim, \& Qu, 2019). The authentic display, also termed genuine emotions, helps reduce emotional exhaustion by eliminating faking and pretense from service interaction (Hulsheger \& Schewe, 2011; Picard, Cossette, \& Morin, 2018).

\section{Hedonic, Eudaimonic, and Physical Well-Being}

Well-being is one of the most important outcomes associated with job demands, emotional exhaustion, and turnover intentions (Heijden, Mahoney, \& Xu, 2019; Rostamabadi et al., 2019; Wolter et al., 2019). Two types of well-being are widely discussed in the literature. First is hedonic well-being, which involves the presence of happiness and pleasure and the absence of anything unpleasant (Diener, Lucas, \& Oishi, 2018). Second is eudaimonic well-being which includes long-term life satisfaction, contentment, meaningfulness, and purpose in life (Ryff, 2018). Eudaimonic well-being is considered longlasting relative to hedonic well-being (Joshanloo, Jovanovic, \& Park, 2020). Physical well-being is also paramount to psychological well-being (Gaetano, 2016; D’Isanto, Manna, \& Altavilla, 2017). An active lifestyle coupled with emotional regulation and social support ensures high physical well-being (Banyard, Hamby, \& Grych, 2017: Lindsay-Smith et al., 2019).

The impact of emotional labor on well-being depends upon the EL strategy being used. Surface acting is often found to reduce well-being (Ryan \& Deci, 2017). However, genuine emotions elevate workers' well-being (Wang, Hall, \& Taxer, 2019). The impact of deep acting remains undecided. In some instances, it may increase well-being since it eliminates dissonance. Conversely, it is straining to employ and thus can reduce well-being (Cheung, Lun, \& Cheung, 2018: Wang, Hall, \& Taxer, 2019).

Applying the JDR and COR theories in the healthcare context, our study hypothesizes that both surface and deep acting are likely to increase emotional exhaustion and cause low well-being among physicians during the pandemic. Those who opt for displaying genuine emotions at work will experience low emotional exhaustion and high well-being.

H1a: Emotional Exhaustion mediates the relationship between Surface Acting and low Hedonic Well-being.

H1b: Emotional Exhaustion mediates the relationship between Surface Acting and low Eudaimonic Well-being.

H1c: Emotional Exhaustion mediates the relationship between Surface Acting and low Physical Well-being.

H2a: Emotional Exhaustion mediates the relationship between Deep Acting and low Hedonic Well-being.

H2b: Emotional Exhaustion mediates the relationship between Deep Acting and low Eudaimonic Well-being.

H2c: Emotional Exhaustion mediates the relationship between Deep Acting and low Physical Well-being.

H3a: Emotional Exhaustion mediates the relationship between Genuine Emotion and high Hedonic Well-being.

H3b: Emotional Exhaustion mediates the relationship between Genuine Emotion and high Eudaimonic Well-being.

H3c: Emotional Exhaustion mediates the relationship between Genuine Emotion and high Physical Well-being.

\section{Social and Enterprising Personality}

A good fit between job and personality not only produces a positive effect on job and organisation (Holland, 1997; Lee, Kim, Kim, \& Kim, 2017; Phan \& Rounds, 2018) but also improves job satisfaction (Törnroos, Jokela, \& Hakulinen, 2019) and increases the chances of career success ( $\underline{\mathrm{Su} \& \mathrm{Nye}, 2017)}$. This study has chosen the personality typology developed by Holland (1959). Out of six, our study has chosen social and enterprising personality types since both the types are theorized to be effective in social settings, teamwork, and taking the initiative (Holland, 1959; 1997). Based upon JDR and COR theories, workers have varying levels of affective resources. Simply put, not every worker would deal with the job's emotional challenges the same way because of different personalities, level of resolve, patience, and psychological capital. Thus, it is proposed that individuals with different personalities will react differently to the emotional component of the job. For some, it may be naturally easy to project the required emotions, unlike others who find it more challenging. Former may have little problem conserving the resources and balancing them to meet job demands, thereby not experiencing emotional exhaustion and low well-being. In contrast, the latter group is more likely to experience exhaustion and subsequent low well-being levels.

Henceforth, keeping in mind the individual differences concerning resilience, emotional composure, and emotional regulation, this study would test the multigroup moderating effect of social and enterprising personalities on the research model. Workers with social personalities are effective in occupations where interaction with people and relationship building are vital to the task's nature. Similarly, workers with enterprising personalities are self-confident and effective in managing and leading teams (Holland, 1959; 1997). Since both these personalities engage more in social and interactive activities, it is reasonable to believe that groups of workers with high versus low degree of social and enterprising 
personality would perform and respond to emotional labor differently during the pandemic. This would aid in clarifying the contingent nature of variables.

H4a: Impact of emotional labor among physicians with high social personality differs from those with a low social personality.

H4b: Impact of emotional labor among physicians with high enterprising personalities differs from those with low enterprising personalities.

\section{Gender as a Multigroup Moderator}

In addition to personality, gender would also be tested for its multigroup moderating effect on the model. Research has shown a significant differential effect of gender on the outcomes of emotional labor. For instance, male workers are less affected by the negative effects of emotional labor than females (Cottingham, Erickson, \& Diefendorff, 2015). Females feel stressed and exhausted due to practising emotional labor relative to their male counterparts (Han et al., 2018). Both males and females respond differently to emotional job demands at work and tackle the implications of emotional labor differently (Simpson \& Stroh, 2004). Based on this premise, this study proposes that males and female physicians would also differ when it comes to the effects of emotional labor during the ongoing pandemic, including emotional exhaustion and wellbeing.

H5: There are significant differences between male and female physicians concerning the impact of emotional labor.

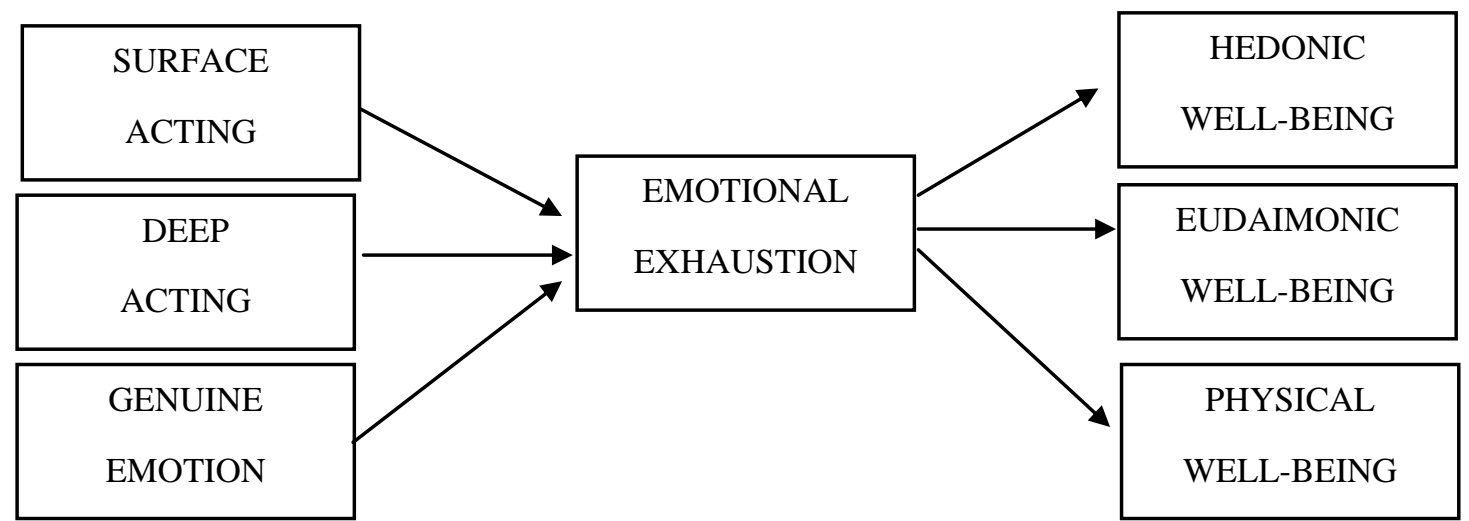

Figure 1: Research Model (Multigroup Moderators: Social-Personality, Enterprising Personality, Gender)

Source: Author Resources

\section{SAMPLE AND METHODS}

Data was collected from 400 physicians working in large hospitals in Islamabad/Rawalpindi, Lahore, Peshawar, Karachi, Bahawalpur, and other cities where the online survey could reach. The Snowball sampling method was adopted to access maximum number of respondents. Structural equation modelling, including serial mediation and multigroup moderation, is employed for data analysis. Emotional labor (surface and deep acting) is measured using 6-item Emotional Labor Scale developed by Brotheridge and Lee (2003). Genuine emotion is measured using a 3-item scale developed by Diefendorff, Croyle, and Gosserand (2005). Scale for emotional exhaustion is adapted from Maslach Burnout Inventory (Maslach \& Jackson, 1981). For measuring hedonic well-being, the scale is adapted from the hedonic well-being instrument developed by the world health organisation (Sell \& Nagpal, 1992). Nine items measuring the Eudaimonic well-being scale are adapted from the instrument developed by Ryff (1989). Seven items measuring physical well-being scale are adapted from the "Perceived Well-Being Scale" developed by Recker and Wong (1984). Lastly, social and enterprising personalities are measured through Holland (1997) personality typology (6 items). AMOS version 23 is used for all statistical analysis.

Table 1: Demographics

\begin{tabular}{lll}
\hline Variables & Options & Frequency \\
\hline Gender & Male & 170 \\
\hline & Female & 225 \\
\hline & Missing & 5 \\
\hline Age Group & $20-30$ & 166 \\
\hline & $31-40$ & 137 \\
\hline & $41-50$ & 42 \\
\hline
\end{tabular}




\begin{tabular}{lll}
\hline & $>50$ & 51 \\
\hline & Missing & 4 \\
\hline Area/Field of Expertise & General Physician & 55 \\
\hline & Internal Medicine & 46 \\
\hline & Dentistry & 38 \\
\hline & ENT & 22 \\
\hline & Dermatology & 22 \\
\hline & Surgery & 75 \\
\hline & Gynaecology & 40 \\
\hline & Cardiology & 2 \\
\hline Experience & Other & 99 \\
\hline & Missing & 1 \\
\hline & $<1$ year & 48 \\
\hline & $1-5$ years & 171 \\
\hline Sector & 6-10 years & 73 \\
\hline & $>10$ years & 99 \\
\hline City & Missing & 9 \\
\hline & Public & 101 \\
\hline & Private & 299 \\
\hline & Islamabad/Rawalpindi & 199 \\
\hline & Lahore & 115 \\
\hline & Karachi & 14 \\
\hline Total & Peshawar & 38 \\
\hline & Bahawalpur & 11 \\
\hline & Other & 23 \\
\hline & & 400 \\
\hline & & \\
\hline & & \\
\hline & & \\
\hline & & \\
\hline & & \\
\hline & &
\end{tabular}

\section{Confirmatory Factor Analysis}

A confirmatory factor analysis was run to examine all scales' validity and reliability in the study. According to Hair et al. (2009), factor loadings for any item must not be below 0.5. However, factor loadings for ewb2, ewb3, ewb4, ewb9, pwb3, and pwb7 were below 0.5. Therefore, they were removed from the model. The final measurement model is shown in Figure 2 , with all items loading above 0.5. Fit indices in table 2 show CFI at 0.901, RMSEA at 0.054, CMIN/DF at 2.144. Values for GFI, AGFI, and NFI are all above 0.8. All these results indicate a good and reliable model fit (Hair et al., 2009).

There is no multicollinearity problem in the model since covariances among all latent variables are less than 0.7. Multicollinearity can cause problems in regression analysis later; thus, it is advised to merge those variables which might be highly correlated (Wanzer et al., 2019). However, the merging should be supported by theory (Dormann et al., 2012). Since both social and enterprising personality types are highly correlated and measured using the same global scale, both are examined as one construct in CFA.

Table 2: CFA Model Fitness

\begin{tabular}{llllllll}
\hline Model & CMIN/DF & GFI & AGFI & NFI & CFI & RMSEA & $\begin{array}{l}\text { Chi-Square } \\
\text { p-value }\end{array}$ \\
\hline 1 & 2.862 & 0.752 & 0.719 & 0.722 & 0.798 & 0.068 & 0.000 \\
\hline 2 & 2.315 & 0.811 & 0.781 & 0.780 & 0.860 & 0.057 & 0.000 \\
\hline 3 & 2.144 & 0.847 & 0.817 & 0.831 & 0.901 & 0.054 & 0.000 \\
\hline
\end{tabular}

\section{Scale Validity and Reliability}

Table 3 shows the validity and reliability of all scales. Composite Reliability (CR) for all scales is above the acceptable threshold of 0.7. Average Variance Extracted (AVE) should be above 0.5 to establish convergent validity (Hair et al., 2009); however, if CR of a scale is above 0.7, AVE above 0.4 is acceptable (Fornell \& Larcker, 1981; Lam, 2012). All Maximum Shared Variance values (MSV) must be less than their corresponding values of AVE to conclude discriminant validity. Hence, all sales are concluded to be valid and reliable. 


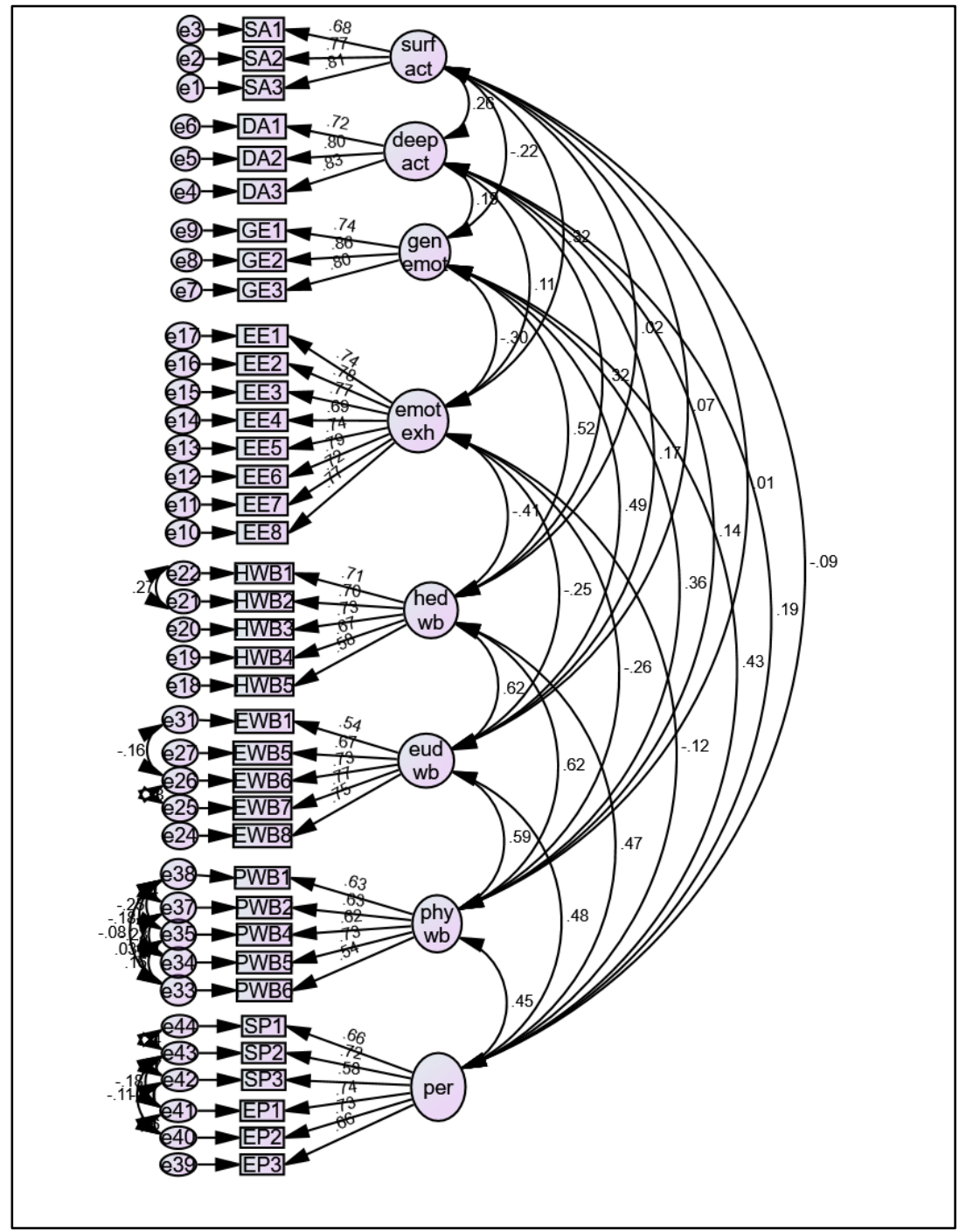

Figure 2: CFA Final Model (Author Resources)

Table 3: Validity and Reliability

\begin{tabular}{|c|c|c|c|c|c|}
\hline Construct & Instrument & $\begin{array}{l}\text { No. of } \\
\text { Items }\end{array}$ & CR & AVE & MSV \\
\hline Surface Acting & $\begin{array}{l}\text { Emotional Labor Scale (Brotheridge \& } \\
\text { Lee, 2003) }\end{array}$ & 3 & 0.798 & 0.569 & 0.099 \\
\hline Deep Acting & $\begin{array}{l}\text { Emotional Labor Scale (Brotheridge \& } \\
\text { Lee, 2003) }\end{array}$ & 3 & 0.828 & 0.617 & 0.104 \\
\hline Genuine Emotions & $\begin{array}{l}\text { Genuine Emotions Scale (Diefendorff, } \\
\text { Croyle, \& Gosserand, 2005) }\end{array}$ & 3 & 0.844 & 0.644 & 0.271 \\
\hline $\begin{array}{l}\text { Hedonic } \\
\text { being }\end{array}$ & $\begin{array}{l}\text { WHO-5 Well-being Scale (Sell \& Nagpal, } \\
\text { 1992) }\end{array}$ & 5 & 0.809 & 0.461 & 0.389 \\
\hline $\begin{array}{l}\text { Eudaimonic Well- } \\
\text { being }\end{array}$ & $\begin{array}{l}\text { Psychological Well-being Scale (Ryff, } \\
\text { 1989) }\end{array}$ & 5 & 0.824 & 0.488 & 0.389 \\
\hline $\begin{array}{l}\text { Physical } \\
\text { being }\end{array}$ & $\begin{array}{l}\text { Perceived Well-being Scale (Recker \& } \\
\text { Wong, 1984) }\end{array}$ & 4 & 0.768 & 0.400 & 0.378 \\
\hline $\begin{array}{l}\text { Emotional } \\
\text { Exhaustion }\end{array}$ & $\begin{array}{l}\text { Maslach Burnout Inventory (Maslach \& } \\
\text { Jackson, 1981) }\end{array}$ & 8 & 0.912 & 0.564 & 0.170 \\
\hline Personality & Holland RIASEC Model (Holland, 1997) & 6 & 0.840 & 0.469 & 0.233 \\
\hline
\end{tabular}




\section{Structural Model}

The structural model highlights the relationships between independent and dependent variables in the model. We have built a latent structural model in figure 3, inclusive of all observed and latent variables. Results reveal that surface and deep acting increase emotional exhaustion. Conversely, genuine emotions reduce emotional exhaustion. Unlike expected, both surface and deep acting have a significant but positive relationship with hedonic, eudaimonic, and physical well-being. Deep acting only has a significant impact on hedonic well-being. As presumed, genuine emotion is found to have a positive effect on well-being dimensions. Regression weights with significance values for all direct paths are shown in table 4. It should be noted here that the study is primarily interested in mediated effects, which are assessed later.



Figure 3: Latent Structural Model

Table 5: Standardized Regression Estimates

\begin{tabular}{lll}
\hline Relationship & Regression Weight & p-value \\
\hline $\mathrm{SA} \rightarrow \mathrm{EE}$ & 0.232 & 0.000 \\
\hline $\mathrm{DA} \rightarrow \mathrm{EE}$ & 0.102 & 0.088 \\
\hline $\mathrm{GE} \rightarrow \mathrm{EE}$ & -0.258 & 0.000 \\
\hline $\mathrm{SA} \rightarrow \mathrm{HWB}$ & 0.231 & 0.000 \\
\hline $\mathrm{SA} \rightarrow \mathrm{EWB}$ & 0.291 & 0.000 \\
\hline $\mathrm{SA} \rightarrow \mathrm{PWB}$ & 0.226 & 0.002 \\
\hline $\mathrm{DA} \rightarrow \mathrm{HWB}$ & 0.219 & 0.000 \\
\hline $\mathrm{DA} \rightarrow \mathrm{EWB}$ & 0.025 & 0.670 \\
\hline $\mathrm{DA} \rightarrow \mathrm{PWB}$ & 0.058 & 0.364 \\
\hline $\mathrm{GE} \rightarrow \mathrm{HWB}$ & 0.474 & 0.000 \\
\hline $\mathrm{GE} \rightarrow \mathrm{EWB}$ & 0.550 & 0.000 \\
\hline $\mathrm{GE} \rightarrow \mathrm{PWB}$ & 0.407 & 0.000 \\
\hline
\end{tabular}




\begin{tabular}{lll}
\hline $\mathrm{EE} \rightarrow \mathrm{HWB}$ & -0.382 & 0.000 \\
\hline $\mathrm{EE} \rightarrow \mathrm{EWB}$ & -0.206 & 0.000 \\
\hline $\mathrm{EE} \rightarrow$ PWB & -0.243 & 0.000 \\
\hline
\end{tabular}

\section{Serial Mediation}

The study seeks to examine the sequential impact of emotional labor strategies on well-being dimensions. The mediator is emotional exhaustion. Mediating effects are calculated using the latent mediation estimand developed by James Gaskin. A bootstrap sample of 1500 is taken to calculate the indirect effects. Results shown in table 5 indicate that surface and deep acting reduce well-being if the relationship is mediated by emotional exhaustion. This satisfies our initial presumption. However, the mediation is only significant for surface acting but insignificant for deep acting. Thus, H1a, H1b, and H1c are supported, and $\mathrm{H} 2 \mathrm{a}, \mathrm{H} 2 \mathrm{~b}$, and $\mathrm{H} 2 \mathrm{c}$ are rejected. As hypothesized, genuine emotion increases well-being via reduced emotional exhaustion. This again confirms the stance that genuine emotional display reduces strain and improves wellbeing. This provides support for $\mathrm{H} 3 \mathrm{a}, \mathrm{H} 3 \mathrm{~b}$, and $\mathrm{H} 3 \mathrm{c}$.

Table 6: Unstandardized Regression Estimates- Serial Mediation

\begin{tabular}{lllll}
\hline Serial Mediation Paths & Estimate & Lower & Upper & p-value \\
\hline $\mathrm{SA} \rightarrow \mathrm{EE} \rightarrow \mathrm{HWB}$ & -.055 & -.106 & -.021 & .003 \\
\hline $\mathrm{SA} \rightarrow \mathrm{EE} \rightarrow \mathrm{EWB}$ & -.032 & -.075 & -.008 & .003 \\
\hline $\mathrm{SA} \rightarrow \mathrm{EE} \rightarrow \mathrm{PWB}$ & -.036 & -.097 & -.012 & .003 \\
\hline $\mathrm{DA} \rightarrow \mathrm{EE} \rightarrow \mathrm{HWB}$ & -.025 & -.064 & .004 & .081 \\
\hline $\mathrm{DA} \rightarrow \mathrm{EE} \rightarrow \mathrm{EWB}$ & -.015 & -.042 & .001 & .059 \\
\hline $\mathrm{DA} \rightarrow \mathrm{EE} \rightarrow \mathrm{PWB}$ & -.017 & -.052 & .000 & .053 \\
\hline $\mathrm{GE} \rightarrow \mathrm{EE} \rightarrow \mathrm{HWB}$ & .069 & .036 & .113 & .001 \\
\hline $\mathrm{GE} \rightarrow \mathrm{EE} \rightarrow \mathrm{EWB}$ & .040 & .016 & .076 & .001 \\
\hline $\mathrm{GE} \rightarrow \mathrm{EE} \rightarrow \mathrm{PWB}$ & .045 & .020 & .091 & .002 \\
\hline
\end{tabular}

\section{Moderated Mediation- Multigroup Effect of Social Personality}

For measuring the multigroup effect of social personality type, firstly, a global test is run to check if the two groups, i.e., physicians with high social personality and physicians with a low social personality, differ on a model level. The test is run using the command of multigroup analysis in AMOS. Table 6 shows the moderator's global effect through a $p$-value smaller than 0.05 that there is a significant difference between the two groups when it comes to the impact of emotional labor on well-being. Hence the hypothesis H4a is supported.

Table 7: Global Effects

\begin{tabular}{llll}
\hline Model & DF & CMIN & $\boldsymbol{P}$ \\
\hline Structural weights & 40 & 83.037 & .000 \\
\hline
\end{tabular}

The local effects highlighted in table 7 point out that when physicians with high social personality engage in surface acting, experience low well-being via emotional exhaustion. The same group experiences low well-being via emotional exhaustion if they display genuine emotions. For physicians with a low social personality, almost all mediation paths are insignificant, signifying no relationship. No difference was found between groups with respect to the impact of deep acting, except on hedonic well-being. The mediation path is significant for the latter group, revealing that physicians with low social personality experience low well-being via emotional exhaustion if they employ deep acting.

Table 8: Local Effects

\begin{tabular}{|c|c|c|c|c|c|c|c|c|}
\hline & Soc High & & & & Soc Low & & & \\
\hline Mediation & Estimate & Lower & Upper & $\mathbf{P}$ & Estimate & Lower & Upper & $\mathbf{P}$ \\
\hline $\mathrm{SA} \rightarrow \mathrm{EE} \rightarrow \mathrm{HWB}$ & -.092 & -.187 & -.034 & .002 & -.017 & -.109 & .004 & .123 \\
\hline $\mathrm{SA} \rightarrow \mathrm{EE} \rightarrow \mathrm{EWB}$ & -.071 & -.140 & -.028 & .002 & .011 & -.015 & .069 & .257 \\
\hline $\mathrm{SA} \rightarrow \mathrm{EE} \rightarrow \mathrm{PWB}$ & -.045 & -.110 & -.010 & .005 & -.008 & -.118 & .014 & .417 \\
\hline $\mathrm{DA} \rightarrow \mathrm{EE} \rightarrow \mathrm{HWB}$ & -.019 & -.082 & .025 & .399 & -.021 & -.083 & .002 & .071 \\
\hline $\mathrm{DA} \rightarrow \mathrm{EE} \rightarrow \mathrm{EWB}$ & -.015 & -.061 & .019 & .388 & .013 & -.009 & .144 & .274 \\
\hline
\end{tabular}




\begin{tabular}{lllllllll}
\hline $\mathrm{DA} \rightarrow \mathrm{EE} \rightarrow \mathrm{PWB}$ & -.010 & -.054 & .010 & .261 & -.009 & -.090 & .015 & .293 \\
\hline $\mathrm{GE} \rightarrow \mathrm{EE} \rightarrow \mathrm{HWB}$ & .119 & .060 & .230 & .002 & .024 & -.001 & .071 & .054 \\
\hline $\mathrm{GE} \rightarrow \mathrm{EE} \rightarrow \mathrm{EWB}$ & .093 & .048 & .168 & .001 & -.015 & -.119 & .012 & .279 \\
\hline $\mathrm{GE} \rightarrow \mathrm{EE} \rightarrow \mathrm{PWB}$ & .058 & .014 & .142 & .005 & .011 & -.026 & .069 & .302 \\
\hline
\end{tabular}

\section{Moderated Mediation- Multigroup Effect of Enterprising Personality}

For conducting multigroup moderating effect of enterprising personality, a similar method was adopted as for social personality. Table 8 shows the moderating effect of enterprising personality on the entire model. P-value less than 0.05 concludes a significant difference between physicians with high enterprising personality and physicians with low enterprising personality, with respect to the impact of emotional labor strategies on well-being dimensions. Hence, hypothesis $\mathrm{H} 4 \mathrm{~b}$ is supported.

Table 9: Global Effect

\begin{tabular}{llll}
\hline Model & DF & CMIN & P \\
\hline Structural weights & 40 & 78.562 & .000 \\
\hline
\end{tabular}

Local effects across the two groups are depicted in Table 9. It shows that the negative impact of surface acting on hedonic and physical well-being is significant for the group with a low enterprising personality, while for a high enterprising personality, the impact is insignificant. For genuine emotions, no differences exist in hedonic well-being. Both groups experience high hedonic well-being when they employ genuine emotions. However, only the group with high enterprising personality experiences high eudaimonic well-being with genuine emotions. Similarly, only the group with a low enterprising personality experience high physical well-being with genuine emotions. Finally, there are no local-level differences between the two groups with respect to the impact of deep acting on well-being.

Table 10: Local Effects

\begin{tabular}{|c|c|c|c|c|c|c|c|c|}
\hline & Ent High & & & & Ent Low & & & \\
\hline $\begin{array}{ll}\text { Serial } & \text { Mediation } \\
\text { Paths } & \\
\end{array}$ & Estimate & Lower & Upper & $\mathbf{P}$ & Estimate & Lower & Upper & $\mathbf{P}$ \\
\hline $\mathrm{SA} \rightarrow \mathrm{EE} \rightarrow \mathrm{HWB}$ & -.089 & -.236 & .021 & .085 & -.042 & -.129 & -.011 & .005 \\
\hline $\mathrm{SA} \rightarrow \mathrm{EE} \rightarrow \mathrm{EWB}$ & -.057 & -.145 & .007 & .063 & -.019 & -.100 & .006 & .144 \\
\hline $\mathrm{SA} \rightarrow \mathrm{EE} \rightarrow \mathrm{PWB}$ & -.007 & -.028 & $\ldots$ & .744 & -.041 & -.142 & -.001 & .038 \\
\hline $\mathrm{DA} \rightarrow \mathrm{EE} \rightarrow \mathrm{HWB}$ & -.022 & -.550 & .063 & .492 & -.028 & -.082 & .006 & .101 \\
\hline $\mathrm{DA} \rightarrow \mathrm{EE} \rightarrow \mathrm{EWB}$ & -.014 & -.311 & .035 & .458 & -.012 & -.071 & .003 & .127 \\
\hline $\mathrm{DA} \rightarrow \mathrm{EE} \rightarrow \mathrm{PWB}$ & -.002 & -.042 & .023 & .719 & -.027 & -.098 & .004 & .100 \\
\hline $\mathrm{GE} \rightarrow \mathrm{EE} \rightarrow \mathrm{HWB}$ & .154 & .024 & .433 & .025 & .047 & .021 & .094 & .004 \\
\hline $\mathrm{GE} \rightarrow \mathrm{EE} \rightarrow \mathrm{EWB}$ & .100 & .019 & .277 & .019 & .021 & -.006 & .068 & .104 \\
\hline $\mathrm{GE} \rightarrow \mathrm{EE} \rightarrow \mathrm{PWB}$ & .011 & $\ldots$ & .049 & .603 & .046 & .008 & .108 & .022 \\
\hline
\end{tabular}

\section{Moderated Mediation- Multigroup Effect of Gender}

The third multigroup moderator in this study is gender. Test for the global effect of gender on the model in table 10 reveals a significant difference between male and female physicians concerning the impact of emotional labor strategies on wellbeing dimensions. This leads to the support of hypothesis H5.

Table 11: Global Effect

\begin{tabular}{llll}
\hline Model & DF & CMIN & P \\
\hline Structural weights & 40 & 61.856 & .015 \\
\hline
\end{tabular}

Looking at the local effects in table 11, it can be observed that the adverse effect of surface acting on well-being is significant for females. Conversely, the impact is insignificant for males. Both male and female physicians experience high hedonic and physical well-being when employing genuine emotions. For eudaimonic well-being, the effect is significant for females only. Lastly, there are no local-level differences between the two groups with respect to the impact of deep acting on well-being. 
Table 12: Local Effects

\begin{tabular}{|c|c|c|c|c|c|c|c|c|}
\hline & Male & & & & Female & & & \\
\hline $\begin{array}{l}\text { Serial Mediation } \\
\text { Paths }\end{array}$ & Estimate & Lower & Upper & $\mathbf{P}$ & Estimate & Lower & Upper & $\mathbf{P}$ \\
\hline $\mathrm{SA} \rightarrow \mathrm{EE} \rightarrow \mathrm{HWB}$ & -.051 & -.155 & .001 & .056 & -.058 & -.332 & -.012 & .005 \\
\hline $\mathrm{SA} \rightarrow \mathrm{EE} \rightarrow \mathrm{EWB}$ & -.019 & -.088 & .005 & .129 & -.047 & -.290 & -.005 & .011 \\
\hline $\mathrm{SA} \rightarrow \mathrm{EE} \rightarrow \mathrm{PWB}$ & -.032 & -.156 & .001 & .054 & -.037 & -.290 & -.001 & .037 \\
\hline $\mathrm{DA} \rightarrow \mathrm{EE} \rightarrow \mathrm{HWB}$ & -.015 & -.104 & .032 & .486 & -.030 & -.074 & .030 & .178 \\
\hline $\mathrm{DA} \rightarrow \mathrm{EE} \rightarrow \mathrm{EWB}$ & -.006 & -.053 & .008 & .314 & -.024 & -.070 & .018 & .159 \\
\hline $\mathrm{DA} \rightarrow \mathrm{EE} \rightarrow \mathrm{PWB}$ & -.009 & -.081 & .011 & .284 & -.019 & -.075 & .009 & .120 \\
\hline GE $\rightarrow$ EE $\rightarrow$ HWB & .075 & .015 & .196 & .015 & .072 & .029 & .151 & .009 \\
\hline GE $\rightarrow$ EE $\rightarrow$ EWB & .027 & -.007 & .110 & .107 & .059 & .020 & .122 & .012 \\
\hline $\mathrm{GE} \rightarrow \mathrm{EE} \rightarrow \mathrm{PWB}$ & .047 & .008 & .156 & .020 & .047 & .008 & .120 & .025 \\
\hline
\end{tabular}

\section{DISCUSSION}

This research aimed towards understanding the behaviour of physicians while practising emotional labor during the COVID-19 pandemic. Differential roles of social and enterprising personalities and gender were examined to assess whether these factors play any role in accentuating or mitigating the impact of emotional labor. Structural equation modelling technique was used to assess the hypothesized relationships. Furthermore, serial mediation analysis and multigroup moderating tests were also used to study in-depth associations among the variables and the global and local differences. Findings suggest a strong association between emotional labor and employee well-being dimensions (Joshanloo, Jovanovic, \& Park, 2020). Both surface and deep acting reduce employee hedonic, eudaimonic, and physical well-being through emotional exhaustion. However, surface acting effects are significant, while effects of deep acting, albeit negative, remain statistically insignificant (Heijden, Mahoney, \& Xu, 2019) Genuine emotions are often regarded as the positive facet of emotional labor and improve all three well-being dimensions by controlling emotional exhaustion.

Multigroup analysis further highlights the role of personality and gender, upon which emotional labor is contingent. Global tests results reveal significant differences between high versus low social personality, high versus low enterprising personality, and male versus female when it comes to the effects of emotional labor on emotional exhaustion and well-being dimensions. For further in-depth analysis, local tests were run for each moderator. Results reveal that physicians with high social personality are more at risk of experiencing low well-being if they engage in surface acting (David, Shoss, Johnson, \& Witt, 2020). The same group is also more likely to experience high well-being if they employ genuine emotions. The reason for this may be those social personalities may be expected to engage in emotional acting, which may take a toll on their well-being. Especially during a pandemic when social distancing is crucial, surface emotional acting is more likely to compromise doctors' well-being. That is why they feel uplifted and experience high well-being when they get to display genuine and authentic emotions. No significant local effects of deep acting on well-being dimensions were found.

Results for the enterprising personality group were somewhat different. Physicians with low enterprising personalities are more vulnerable to low hedonic and physical well-being if they engage in surface acting (Chen, Chang, \& Wang, 2019). This might be because an enterprising personality entails leadership and confidence, which this group lacks. Thus, this group would find surface acting more tiring and challenging. For doctors displaying genuine emotions, no difference was found between high versus low enterprising personality with respect to hedonic well-being. However, a high enterprising personality leads to higher eudaimonic well-being, whereas a low enterprising personality leads to higher physical wellbeing when genuine emotions are displayed. The former effect is understandable as doctors with leading skills are naturally and genuinely effective in leadership roles. Thus they need not display emotional acting and therefore experience high eudaimonic well-being. Similarly, doctors with low enterprising are not naturally prone to leadership roles. Thus displaying genuine emotions may compromise their eudaimonic well-being but improve their physical well-being. No significant local effects of deep acting on well-being dimensions were found.

Finally, the results from the moderating effect of gender show that female doctors experience low hedonic, eudaimonic and physical well-being when engaging in surface acting. Conversely, no significant effect of surface acting was found on wellbeing dimensions among male doctors. Both male and female doctors experience high well-being levels when they display genuine emotions. However, the impact of genuine emotions on eudaimonic well-being was not significant among male doctors. No significant local effects of deep acting on well-being dimensions were found concerning gender. 
The role of genuine emotions in enhancing well-being is similar across both groups. For deep acting, there is seldom difference across all groups. This is because deep acting has not been found to significantly affect well-being in the mediation paths for the entire population. Our results are similar to those of Cottingham, Erickson, and Diefendorff (2015), Cheung, Lun, and Cheung (2018), Han et al. (2018), and Wang, Hall, and Taxer (2019).

\section{CONCLUSION AND RESEARCH IMPLICATIONS}

Our study investigated the differential role of personality and gender on emotional labor, emotional exhaustion, and wellbeing model in the healthcare context. The findings point out the need to understand how personality can affect workers' well-being at work. An employee's personality must be in sync with the nature of tasks and challenges they face daily. Especially in the hospital sector, workforce needs to possess ample affective and emotional resources to combat their jobs' emotional demands, especially during the COVID pandemic. The same principle applies to the role of gender. Organizations need to determine the drivers of emotional exhaustion and well-being for both males and females. Only in this way can a customized response be prepared for every group to eliminate the damaging outcomes. Emotionally, mentally, and physically detrimental factors associated with COVID-19 pandemic can be dealt with more effectively if right people are selected for the job. On the other hand, measures can be taken to combat the emerging issues and challenges tied to the pandemic. Henceforth, this study would help healthcare organisations make the right choices during the recruitment and selection process to choose the most suitable candidates, i.e., ones whose personality and gender attributes are aligned with their field of work. Not doing so runs the risk of burnout, stressed, and demotivated workforce.

\section{LIMITATIONS \& FUTURE RESEARCH}

There are numerous avenues for future researches which were not pursued given limitations of time and resources. A longitudinal study tapping into the same constructs would explain the temporal behaviour of all variables. Role of age or other variables can further uncover how various age groups practice emotional labor and experience its outcomes. New insights can be unfolded if mixed method research is employed to explore emotional labor and related constructs. Last, having lived a year with the pandemic, upcoming research can investigate longitudinal effects of variables by comparing the first and second waves of the COVID-19 pandemic.

\section{STATEMENT OF COMPETING INTERESTS}

This statement is to certify that the authors of this research hereby declare no competing interests regarding this article's publication.

\section{AUTHOR CONTRIBUTION}

Saman Javed contributed to developing the research framework and performed the statistical analyses, interpretations, and technical parts. Noshaba Batool contributed to designing the organization of the article and writing the study's discussion, conclusion, and research implications. All the author(s) have a significant contribution to the research article.

\section{ACKNOWLEDGEMENT}

We would like to thank all the independent reviewers of HSSR who conducted a feasibility study of our research work.

\section{REFERENCES}

1. Aschwanden, D., Strickhouser, J.E., Sesker, A.A., Lee, J.H., Luchetti, M., Stephan, Y., Sutin, A.R., \& Terracciano, A. (2020). Psychological and behavioural responses to coronavirus disease 2019: The role of personality. European Journal of Personality. https://doi.org/10.1002/per.2281

2. Ashforth, B.E., and Humphrey, R.H. (1993). Emotional labor in service roles: The influence of identity. Academy of Management Review, 18(1), 88-115. https://doi.org/10.2307/258824

3. Banyard, V., Hamby, S., \& Grych, J. (2017). Health effects of adverse childhood events: Identifying promising protective factors at the intersection of mental and physical well-being. Child Abuse \& Neglect, 65, 88-98. https://doi.org/10.1016/i.chiabu.2017.01.011

4. Bhuyan, A. (2020). Caring for the carers during the Covid-19 pandemic. (Retrieved from https://www.livemint.com/mint-lounge/features/caring-for-the-carers-during-the-covid-19-pandemic11586265288300.html

5. Brotheridge, C.M., \& Lee, R.T. (2003). Development and validation of the emotional labor scale. Journal of Occupational and Organizational Psychology, 76(3), 365-79. https://doi.org/10.1348/096317903769647229

6. Chen, K.Y., Chang, C-W., \& Wang, C-H. (2019). Frontline employees' passion and emotional exhaustion: the mediating role of emotional labor strategies. International Journal of Hospitality Management, 76, 163-172. https://doi.org/10.1016/j.ijhm.2018.05.006 
7. Cheung, F., Lun, V.M.C., \& Cheung, M.W-L. (2018). Emotional labor and occupational well-being: latent profile transition analysis approach. Frontiers in Psychology, 9. https://doi.org/10.3389/fpsyg.2018.01084

8. Cottingham, M.D., Erickson, R.J., \& Diefendorff, J.M. (2015). Examining men's status shield and status bonus: How gender frames the emotional labor and job satisfaction of nurses. Sex Roles, 72(7-8), 377-389. https://doi.org/10.1007/s11199-014-0419-Z

9. D'Isanto, T., Manna, A., \& Altavilla, G. (2017). Health and physical activity. Sport Science, 10(1), 100-105.

10. David, E.M., Shoss, M.K, Johnson, L.U., \& Witt, L.A. (2020). Emotions running high: Examining the effects of supervisor and subordinate emotional stability on emotional exhaustion. Journal of Research in Personality, 84. https://doi.org/10.1016/j.jrp.2019.103885

11. Demerouti, E., Bakker, A.B., Nachreiner, F. \& Schaufeli, W.B. (2001). The Job Demands-Resources Model of Burnout, Journal of Applied Psychology, 86(3), 499-512.

12. Diefendorff, J.M., Croyle, M.H., \& Gosserand, R.H. (2005). The dimensionality and antecedents of emotional labor strategies. Journal of Vocational Behavior, 66(2), 339-357. https://doi.org/10.1016/j.jvb.2004.02.001

13. Diener, E., Lucas, R. E., \& Oishi, S. (2018). Advances and open questions in the science of subjective well-being. Collabra: Psychology, 4(1). https://doi.org/10.1525/collabra.115

14. Dormann, C. F. et al. (2013). Collinearity: a review of methods to deal with it and a simulation study evaluating their performance. Ecography, 36, 27-46. https://doi.org/10.1111/j.1600-0587.2012.07348.x

15. Fornell, C., \& Larcker, D.F. (1981). Evaluating structural equation models with unobservable variables and measurement error. Journal of Marketing Research, 18(1) 39-50. https://doi.org/10.2307/3151312

16. Gabriel, A., Acosta, J. \& Grandey, A. (2015). The Value of a Smile: Does Emotional Performance Matter More in Familiar or Unfamiliar Exchanges? Journal of Business Psychology, 30(1), 37-50. https://doi.org/.1007/s10869013-9329-2

17. Gaetano, A. (2016). Relationship between physical inactivity and effects on individual health status. Journal of Physical Education and Sport, 16(2), 1069-1074. https://doi.org/10.7752/jpes.2016.s2170

18. Golparvar, M. (2016). Unconventional functions of deviant behaviors in the relationship between job stress and emotional exhaustion: Three study findings. Current Psychology, 35(3), 269-284. https://doi.org/10.1007/s12144014-9292-8

19. Gulsen, M., \& Ozmen, D. (2019). The relationship between emotional labour and job satisfaction in nursing. International Nursing Review, 67(1), 145-154. https://doi.org/10.1111/inr.12559

20. Hair, J.F., Black, W.C., Babin, B.J., \& Anderson, R.E. (2009). Multivariate data analysis. A global perspectiveSeventh edition. Upper Saddle River: Prentice Hall.

21. Han, K-M., Shin, C., Yoon, H-K., Ko, Y-H., Kim, Y-K., and Han, C. (2018). Emotional labor and depressive mood in service and sales workers: Interactions with gender and job autonomy. Psychiatry Research, 267, 490-498. https://doi.org/10.1016/j.psychres.2018.06.044

22. Heijden, B.V., Mahoney, C.B., \& Xu, Y. (2019). Impact of job demands and resources on nurses' burnout and occupational turnover intention towards an age-moderated mediation model for the nursing profession. International Journal of Environmental Research and Public Health, 16(11), https://doi.org/10.3390/ijerph16112011

23. Hobfoll, S. E. (1989). Conservation of resources: A new attempt at conceptualizing stress. American Psychologist, 44(3), 513-524. https://doi.org/10.1037/0003-066X.44.3.513

24. Hobfoll, S.E. (2011). Conservation of resource caravans and engaged settings. Journal of Occupational and Organizational Psychology, 84(1), 116-122. https://doi.org/10.1111/j.2044-8325.2010.02016.x

25. Hobfoll, S.E., Halbesleben, J., Neveu, J-P., \& Westman, M. (2018). Conservation of resources in the organizational context: The reality of resources and their consequences. Annual Review of Organizational Psychology and Organizational Behavior, 5, 103-128. https://doi.org/10.1146/annurev-orgpsych-032117-104640

26. Hochschild, A. (1979). Emotion work, feeling rules, and social structure. American Journal of Sociology, 85(3), 551-575.

27. Holland, J. L. (1959). A theory of vocational choice. Journal of Counseling Psychology, 6(1), 35-45. https://doi.org/10.1037/h0040767

28. Holland, J. L. (1997). Making vocational choices: A theory of vocational personalities and work environments. Odessa, FL, US: Psychological Assessment Resources.

29. Hu, H-H., Hu, H-Y., \& King, B. (2017). Impacts of misbehaving air passengers on frontline employees: Role stress and emotional labor. International Journal of Contemporary Hospitality Management, 29(7), 1793-1813. https://doi.org/10.1108/IJCHM-09-2015-0457

30. Hulsheger, U.R. \& Schewe, A.F. (2011). On the Costs and Benefits of Emotional Labor: A Meta-Analysis of Three Decades of Research. Journal of Occupational Health Psychology, 16(3), 361-389. https://doi.org/10.1037/a0031313 
31. Hur, W-M., Moon, T., \& Jun, J-K. (2016). The effect of workplace incivility on service employee creativity: The mediating role of emotional exhaustion and intrinsic motivation. Journal of Services Marketing, 30(3), 302-315. https://doi.org/10.1108/JSM-10-2014-0342

32. Jeronimus, B.F. (2020). Personality and the Coronavirus Covid-19 Pandemic. University of Groningen Press, Groningen, Netherlands.

33. Joshanloo, M., Jovanovic, V., \& Park, J. (2020). Differential relationships of hedonic and eudaimonic well-being with self-control and long-term orientation. Japanese Psychological Research. https://doi.org/10.1111/jpr.12276

34. Khalid, A., \& Ali, S. (2020). COVID-19 and its Challenges for the Healthcare System in Pakistan. Asian Bioethics Review, 12, 551-564. https://doi.org/10.1007/s41649-020-00139-x

35. Lam, L. W. (2012). Impact of competitiveness on salespeople's commitment and performance. Journal of Business Research, 65(9), 1328-1334 https://doi.org/10.1016/j.jbusres.2011.10.026

36. Lee, Y., Kim, S., Kim, M. and Kim, H. (2017). Person-environment fit and its effects on employees' emotions and self-rated/supervisor-rated performances: The case of employees in luxury hotel restaurants. International Journal of Contemporary Hospitality Management, 29(5), 1447-1467. https://doi.org/10.1108/IJCHM-08-2015-0441

37. Lindsay-Smith, G., Eime, R.E., O’Sullivan, G., Harvey, J., \& Uffelen, J. (2019). A mixed-methods case study exploring the impact of community-run physical activity programs on physical well-being in older adults. $B M C$ Geriatrics, 19. https://doi.org/10.1186/s12877-019-1245-5

38. Liu, H., Zou, H-Y., Wang, H-J., Xu, X., \& Liao, J-Q. (2019). Do emotional labour strategies influence emotional exhaustion and professional identity or vice versa? Evidence from new nurses. Journal of Advanced Nursing. 76(2), 577-587. https://doi.org/10.1111/jan.14266

39. Maslach, C., \& Jackson, S. E. (1981). The measurement of experienced burnout. Journal of Organizational Behavior, 2(2), 99-113. https://doi.org/10.1002/job.4030020205

40. Maslach, C., \& Leiter, M. P. (2016). Burnout. In G. Fink (Ed.), Stress: Concepts, cognition, emotion, and behaviour: Handbook of stress (pp. 351-357). San Diego, CA: Academic Press.

41. Maslach, C., Schaufeli, W. B., \& Leiter, M. P. (2001). Job burnout. In S. T. Fiske, D. L. Schacter, \& C. ZahnWaxler (Eds.), Annual Review of Psychology, 52(1), (pp. 397-422). https://doi.org/10.1146/annurev.psych.52.1.397

42. McCauley, K.D., \& Gardner, W.L. (2015). Separated from the self: A conceptual model of the emotional labordishonesty relationship [Abstract]. Academy of Management Proceedings, 2015(1). https://doi.org/10.5465/ambpp.2015.17494abstract

43. Murthy, S., Gomersall, C.D. \& Fowler, R.A. (2020). Care for Critically Ill Patients with COVID-19. Clinical Review \& Education- JAMA Insights. https://doi.org/10.1001/jama.2020.3633

44. Phan, W.M.J. \& Rounds, J. (2018). Examining the duality of Holland's RIASEC types: Implications for measurement and congruence. Journal of Vocational Behavior, 106, 22-36. https://doi.org/10.1016/j.jvb.2017.11.011

45. Picard, K., Cossette, M., \& Morin, D. (2018). Service with a smile: A source of emotional exhaustion or performance incentive in call-centre employees. Canadian Journal of Administrative Sciences, 35(2), 214-227. https://doi.org/10.1002/cjas.1413

46. Recker, G.T., \& Wong, P.T.P. (1984). Psychological and physical well-being in the elderly: The perceived wellbeing scale (PWB). Canadian Journal on Aging, 3(1), 23-32. https://doi.org/10.1017/S0714980800006437

47. Rostamabadi, A., Shouroki, F.K., Jalilian, H., Chhobineh, A., Azmoon, H., \& Shakerian, M. (2019). The relationship between work-related psychosocial factors and burnout among Iranian nurses: job demand-controlsupport model. La Medicina del Lavoro, 110(4), 312-320. https://doi.org/10.23749/mdl.v110i4.8025

48. Ryan, R. M., \& Deci, E. L. (2017). Self-determination theory: Basic psychological needs in motivation, development, and wellness. New York, NY: Guilford Publishing.

49. Ryff, C. D. (2018). Well-being with soul: Science in pursuit of human potential. Perspectives on Psychological Science, 13, 242-248. https://doi.org/10.1177/1745691617699836

50. Ryff, C.D. (1989). Happiness Is everything, or is it? Explorations on the meaning of psychological well-being. Journal of Personality and Social Psychology, 57(6), 1069-1081. https://doi.org/10.1037/0022-3514.57.6.1069

51. Sell, H. \& Nagpal, R. (1992). Assessment of Subjective Well-Being: The Subjective Well-Being Inventory (SUBI). New Delhi: Regional Office for South-East Asia, World Health Organization.

52. Shaukat, N., Ali, D.M., \& Razzak, J. (2020). Physical and mental health impacts of COVID-19 on healthcare workers: a scoping review. International Journal of Emergency Medicine, 13. https://doi.org/10.1186/s12245-02000299-5

53. Shreffler, J., Petrey, J., \& Huecker, M. (2020). The Impact of COVID-19 on Healthcare Worker Wellness: A Scoping Review. Western Journal of Emergency Medicine, 21(5), 1059-1066. https://doi.org/10.5811/west jem.2020.7.48684 
54. Simpson, P.A. and Stroh, L.K. (2004). Gender differences: emotional expression and feelings of personal inauthenticity. Journal of Applied Psychology, 89(4), 715-721. https://doi.org/10.1037/0021-9010.89.4.715

55. Sinnott, C., Georgiadis, A., Park, J. \& Dixon-Woods, M. (2020). Impacts of Operational Failures on Primary Care Physicians' Work: A Critical Interpretive Synthesis of the Literature. Annals of Family Medicine, 18(2), 159-168. https://doi.org/10.1370/afm.2485

56. Su, R., \& Nye, C. D. (2017). Interests and person-environment fit: A new perspective on workforce readiness and success. In J. Burrus, K. D. Mattern, B. D. Naemi, \& R. D. Roberts (Eds.), Building better students: Preparation for the workforce (p. 177-206). Oxford University Press.

57. Törnroos, M., Jokela, M. \& Hakulinen, C. (2019). The relationship between personality and job satisfaction across occupations. Personality and Individual Differences, 145, 82-88. https://doi.org/10.1016/j.paid.2019.03.027

58. Volk, A.A., Brazil, K.J., Franklin-Luther, P., Dane, A.V., \& Vaillancourt, T. (2021). The influence of demographics and personality on COVID-19 coping in young adults. Personality and Individual Differences, 168. https://doi.org/10.1016/j.paid.2020.110398

59. Wang, H., Hall, N.C., \& Taxer, J.L. (2019). Antecedents and consequences of teachers' emotional labor: a systematic review and meta-analytic investigation. Educational Psychology Review, 31, 663-698. https://doi.org/10.1007/s10648-019-09475-3

60. Wanzer, D., McKlin, T., Edwards, D., Freeman, J. and Magerko, B. (2019). Assessing the attitudes towards computing scale: A survey validation study. SIGCSE, Proceedings of the 50th ACM Technical Symposium on Computer Science Education. 859-865. https://doi.org/10.1145/3287324.3287369

61. Wolter, C., Maria, A.S.., Wörfel, F., Guys, B., Lesener, T., Kleibler, D., \& Renneberg, B. (2019). Job demands, job resources, and well-being in police officers- A resource-oriented approach. Journal of Police and Criminal Psychology, 34, 45-54. https://doi.org/10.1007/s11896-018-9265-1

62. Yin, H., Huang, S., \& Lv, L. (2018). A multilevel analysis of job characteristics, emotion regulation, and teacher well-being: A job demands-resources model. Frontiers in Psychology, 9. https://doi.org/10.3389/fpsyg.2018.02395

63. Yu, Y., Kim, H., \& Qu, H. (2020). A deep acting perspective generation Y hotel employees' workplace deviance. International Journal of Contemporary Hospitality Management, 32(2), 835-852. https://doi.org/10.1108/IJCHM$\underline{05-2019-0426}$

64. Zhan, Y., Wang, M., \& Shi, J. (2016). Interpersonal process of emotional labor: The role of negative and positive customer treatment. Personnel Psychology, 69(3), 525-557. https://doi.org/10.1111/peps.12114 